\title{
MODIFICATIONS ALSI7MG0.3 ALLOYS TROUGH CA, SR AND SB
}

\author{
Jaromír Cais' ${ }^{1}$ Irena Lysoňková', Pavel Kraus \\ 1 J.E. Purkyně University in Ústí nad Labem, Faculty of Production Technology and Management, Pasteurova \\ 3334/7, 40001 Ústí nad Labem, Czech Republic, e-mail: cais@fvtm.ujep.cz, lysonkova@fvtm.ujep.cz, kraus@ \\ fvtm.ujep.cz
}

Received: 2018.04.19

Accepted: 2018.05.08 Published: 2018.06.01

\begin{abstract}
This article deals with examing the effect of modifier on changes in microstructure of the alloy AlSi7Mg0.3. The content of the experiment was to examine the effect of addition of calcium, stroncium, and antimony to change the morphology of the eutectic silicon in the alloy type of Al-Si (namely AlSi7Mg0.3). Besides changes in the morphology of eutectic silicon was explored focused on character exlusion modifiers within microstructure of the modified alloy. Examination of the microstructure was realized by scanning electron microscopy and complemented by EDX analysis of the examined samples.
\end{abstract}

Keywords: Al-Si alloy, modifier, microstructure, EDX analysis

\section{INTRODUCTION}

Alloys of the type Al-Si were first technicaly reported in 1856 . The focus of attention in the field technical practice to get the early 1920s, when in 1920 the USA presented Aladar Pacz alloy based on Al-Si with the brand name Alpax. It was an aluminum alloy containing $15 \% \mathrm{Si}$. Its use has found this alloy in the beginning of castings used in automotive industry (especially in Germany and France). Already at the beginning of its discovery in $1921 \mathrm{Pacz}$ described the silumin effect (modification prosess in Al-Si alloys), this proces at the time od alkali metals (sodium and potassium) into melt Al-Si alloys by salt these elements. The modification proces was patented of Pacz in 1932 in the USA under name Treatment of Aluminium - Silicon alloys (US1828797), when the recommended content the addition of alkali metal to the melt determined to be 0.05 to 0.2 wt. $\%$. The content of this patent is to describe the mechanism of modification, which due to the addition of alkali metal is changet morphology of silica particles in the microstructure of the examined alloys (Si content from the 3-35\%) of needles into a small round particles [1].
From the very beginning Modification Application Al-Si alloys, researchers have tried to describe this process. While their attention was primarily focussed on the modification of these alloys by sodium. The most important researchers in this area during the 20th century figured, were: Edwards Archer Phillips (in the 20s), Tsumari (in the 50s) A Mondolfo (during 60s).

Difficulty dosage of sodium, a short-term effect of modifying in the melt caused by evaporation and the related increase in gas content, were arguments for seeking compensation for that element. Based on research results, Hesse and Latkowski developed signatures based on strontium, that as a modifier were gradually replaced by sodium. In the mid 70s Jenkinson and Hogan made research aimed to explore modification of Al-Si alloys by strontium (like Day and Hogan in 1968). In his research Jankinson and Hogan used the examination of the sample after anodic oxidation under polarized light microscope so that they observe the morphology of the grains of $\alpha$ phase. The research showed that grain in the unmmodified alloy are finer than in the case of using modifier. Furthermore in the unmodified alloy are equiaxed grains in the longitudinal and trans- 
verse direction, whereas in the modified alloy grains are oriented in the growth direction. The result of observation is an indirect confirmation that in the unmodified alloy is first to crystallization of silicon and grains of $\alpha$ phase then created as equiaxed between formed the plates of silicon. In contrast, in the modified alloy occurs by these researchers work to slow crystal growth of silicon and because present production and growth of dendrites of $\alpha$-phase silicon fibers. Through these and many other efforts during the 60 s and 70 s of the 20th century failed to find a unifying theory of kinetic modification of Al-Si alloys. The following decade was marked by efforts to find this theory, and in this period was the creation of two different of thought describing the creation and modification of eutectic in the Al-Si [1,3].

$\mathrm{Lu}$ and Hallawel in 1987 presented twins theory, which describes the theoretical principle by the modification of Al-Si alloys and soon became a widely accepted theory of modification. This theory is based on the adsorption of the active substance (modifier) to the surface embryo of the crystallizing stage (silicon), thus it will prevent access to other silicon atoms. Adsorption modifier onto the fiber crystallizing silicon same time causes the formation of twins around the crystallising fiber $[1,2]$.

\section{DESCRIPTION OF THE EXPERIMENT}

To prepare samples for subsequent examination of the microstructure batches consisting from ingots of $\mathrm{Al}$ (purity 99.8\%), pure $\mathrm{Si}$ and pure $\mathrm{Mg}$ were used. The batch was for each variant casting (with and without addition of modifier), calculated on the weight of $1000 \mathrm{~g}$. Were clause 4 variants of samples: AlSi7Mg0.3 alloy without the addition of a modifier alloy modified with strontium, calcium modified alloy, an alloy of antimony modified. Modification of the alloy was carried out by master alloy in the concentration of $10 \mathrm{wt} . \%$ content of eachmodifier in master alloy (AlSr10, AlCa10 and AlSb10). The optimal content of each modifier in the alloy was determined based on literature sources and previous research: $\mathrm{Sr} 0.02$ to 0.05 wt. $\% \mathrm{Ca}$ from 0.10 to 0.15 wt. $\% \mathrm{Sb} \mathrm{Ca}$ from 0.10 to 0.15 wt. $\%$.

The batch of primary alloy was realized in electric resistence funance in graphite crucibles (at $740^{\circ} \mathrm{C}$ ). After melting of the batch has been cleaned by refining molten salt and the subsequent withdrawal smears. After cleaning of the melt has been modified by adding modifiers to samples in the form of master alloys.

Casting the individual samples was performed at $720^{\circ} \mathrm{C}$. Molding was carried out technology of gravity casting into a preheated metal mold (mold preheated to a temperature of $200^{\circ} \mathrm{C}$ ), four cylindrical cavities. The resulting cast was shaped like a cylinder with a diameter of $19 \mathrm{~mm}$, a length of $210 \mathrm{~mm}$ and weighing about 180 grams.

Table 1. The chemical composition of Al alloy

\begin{tabular}{|c|c|c|c|c|c|c|c|c|c|c|c|}
\hline Element & $\mathbf{S i}$ & $\mathbf{F e}$ & $\mathbf{C u}$ & $\mathbf{M n}$ & $\mathbf{M g}$ & $\mathbf{N i}$ & $\mathbf{T i}$ & $\mathbf{S r}$ & $\mathbf{S b}$ & $\mathbf{C a}$ & $\mathbf{A l}$ \\
\hline Content [wt.\%] & 7.305 & 0.086 & $<0.001$ & $<0.020$ & 0.260 & 0.0036 & 0.0044 & $<0.001$ & $<0.007$ & 0.0047 & residue \\
\hline
\end{tabular}

Table 2. The chemical composition of the alloy AlSi7Mg0,3 (modifies strontium)

\begin{tabular}{|c|c|c|c|c|c|c|c|c|c|c|c|}
\hline Element & $\mathbf{S i}$ & $\mathbf{F e}$ & $\mathbf{C u}$ & $\mathbf{M n}$ & $\mathbf{M g}$ & $\mathbf{N i}$ & $\mathbf{T i}$ & $\mathbf{S r}$ & $\mathbf{S b}$ & $\mathbf{C a}$ & $\mathbf{A l}$ \\
\hline Content [wt.\%] & 7.252 & 0.163 & 0.057 & $<0.020$ & 0.268 & 0.0065 & 0.0039 & 0.027 & $<0.007$ & 0.004 & residue \\
\hline
\end{tabular}

Table 3. The chemical composition of the alloy AlSi7Mg0,3 (modifies calcium)

\begin{tabular}{|c|c|c|c|c|c|c|c|c|c|c|c|}
\hline Element & $\mathbf{S i}$ & $\mathbf{F e}$ & $\mathbf{C u}$ & $\mathbf{M n}$ & $\mathbf{M g}$ & $\mathbf{N i}$ & $\mathrm{Ti}$ & $\mathbf{S r}$ & $\mathbf{S b}$ & $\mathbf{C a}$ & $\mathbf{A l}$ \\
\hline Content [wt.\%] & 7.252 & 0.163 & 0.057 & $<0.020$ & 0.268 & 0.0065 & 0.0039 & 0.027 & $<0.007$ & 0.004 & residue \\
\hline
\end{tabular}

Table 4. The chemical composition of the alloy AlSi7Mg0,3 (modifies antimony)

\begin{tabular}{|c|c|c|c|c|c|c|c|c|c|c|c|}
\hline Element & $\mathbf{S i}$ & $\mathbf{F e}$ & $\mathbf{C u}$ & $\mathbf{M n}$ & $\mathbf{M g}$ & $\mathbf{N i}$ & $\mathbf{T i}$ & $\mathbf{S r}$ & $\mathbf{S b}$ & $\mathbf{C a}$ & $\mathbf{A l}$ \\
\hline Content [wt.\%] & 7.178 & 0.191 & $<0.001$ & $<0.020$ & 0.268 & $<0.020$ & 0.0049 & $<0.001$ & 0.121 & 0.0019 & residue \\
\hline
\end{tabular}




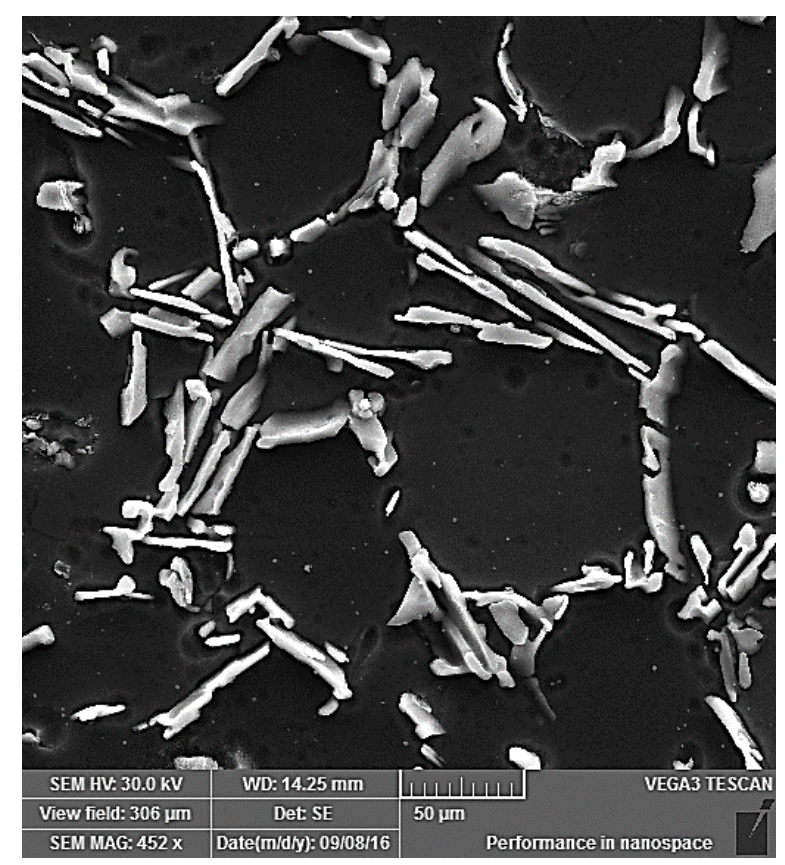

Fig. 1. Eutectic alloys AlSi7Mg0.3 in unmodified state (SEM)

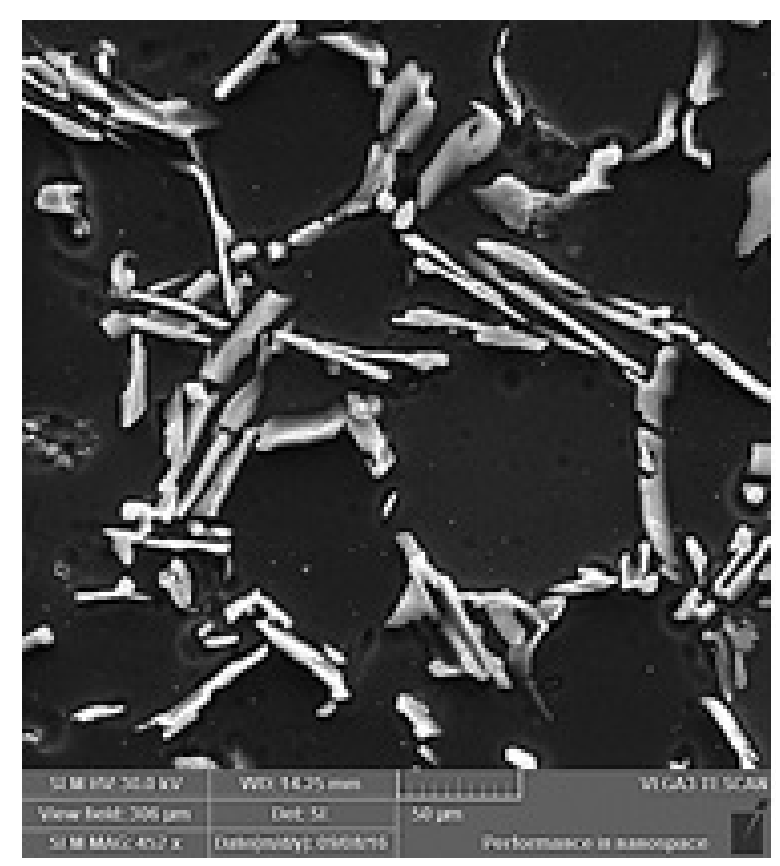

Fig. 2. Eutectic alloys AlSi7Mg0.3 in unmodified state (SEM)

After casting analyses of chemical composition were performed on each samples, realized by optical optical emission spectrometer Q4 TASMAN. The results of chemical composition of each samples are shown in Tab. $1-4$. The recorded values of the individual elements are arithmetic means of 5 measurements.

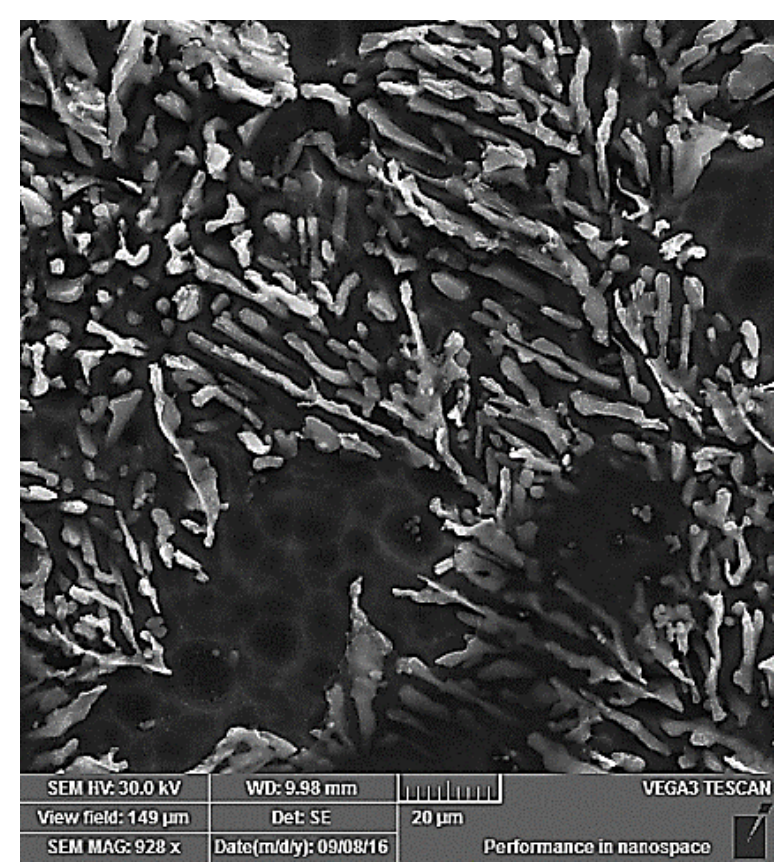

Fig. 3. Eutectic alloys AlSi7Mg0.3 modified strontium (SEM)

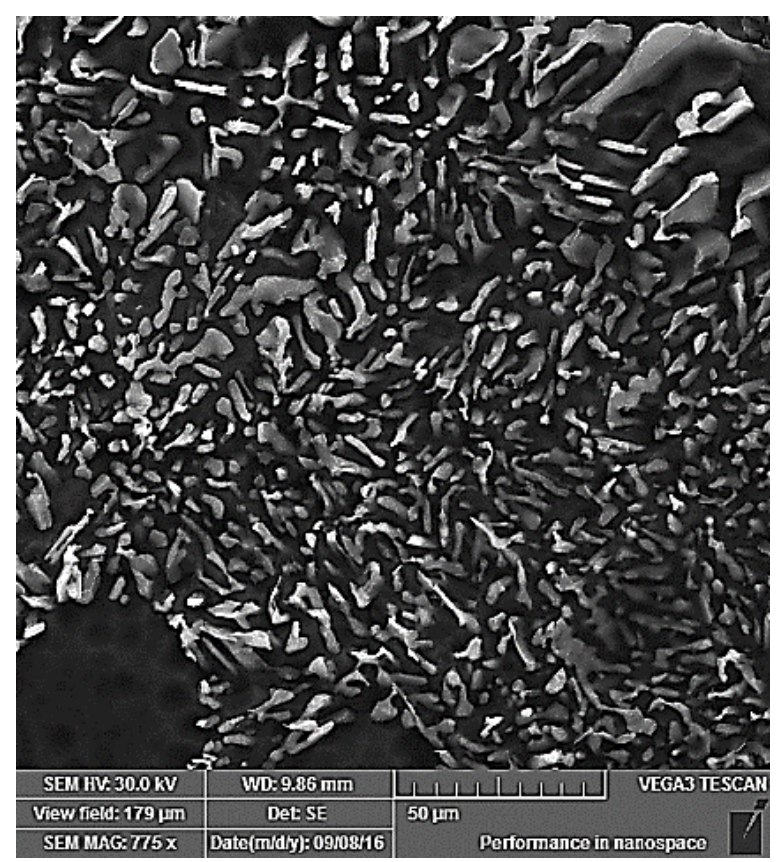

Fig. 4. Eutectic alloys AlSi7Mg0.3 modified strontium (SEM)

\section{MICROSTRUCTURE ANALYSIS - SEM AND EDX ANALYSIS}

To examine the microstructure a scanning electron microscope TESCAN VEGA 3 was used, wherein the analysis focused on documenting the morphology of the separated par- 


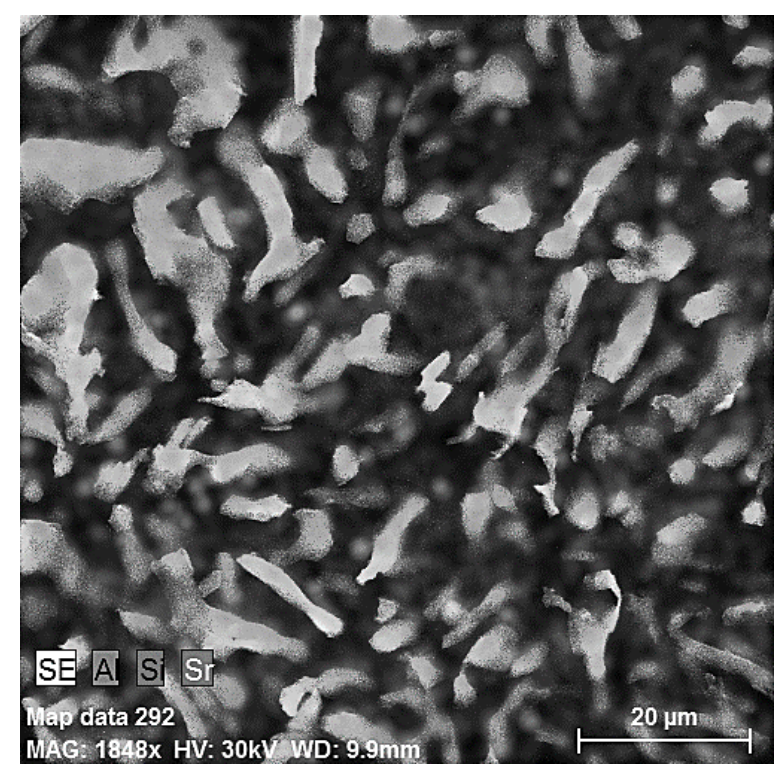

Fig. 5. Elemental map eutectic after modification strontium

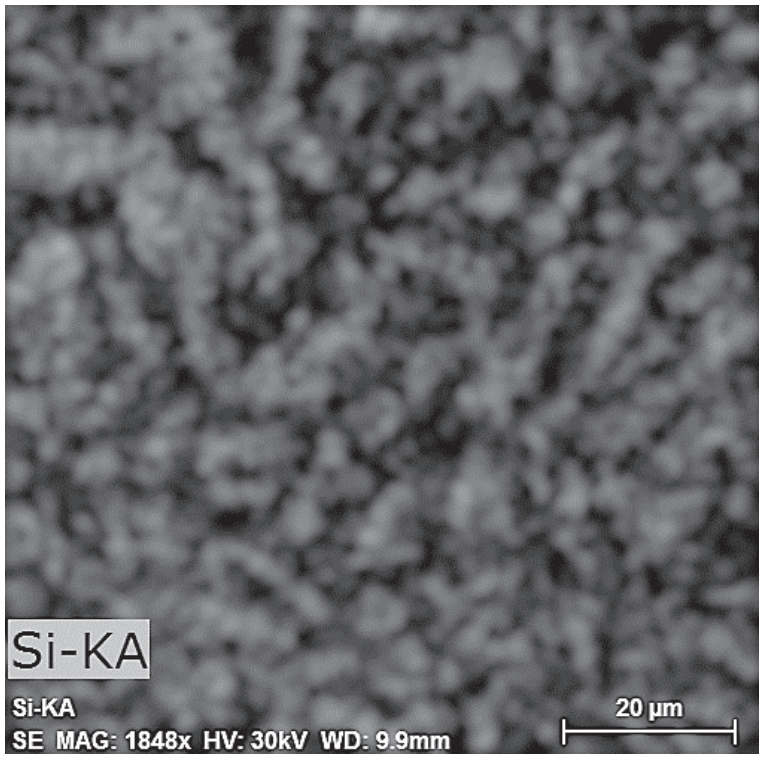

Fig. 6. Elemental map eutectic after modification strontium - silicon

ticles of eutectic silicon, depending on which modifier is used. A subsequent EDX analysis conducted by EDX analyzer Bruker X-Flash, which was equipped with a microscope. This analysis focused on examining distribution of concentration modifiers within the microstructure modified samples, or their distribution within the eutectic. To visualize the morphology of the eutectic process deep etching was used, when the samples were subjected to

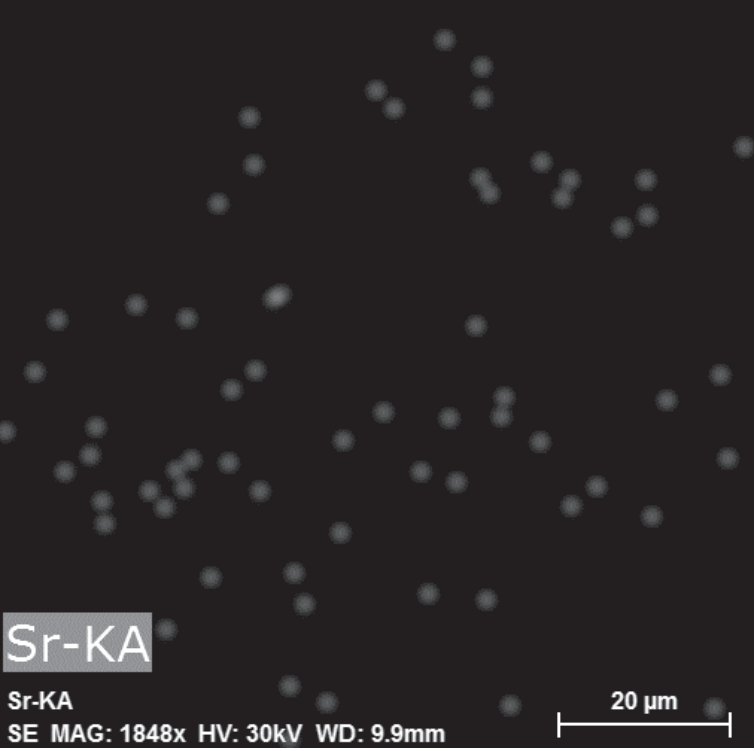

Fig. 7. Elemental map eutectic after modification strontium - strontiium

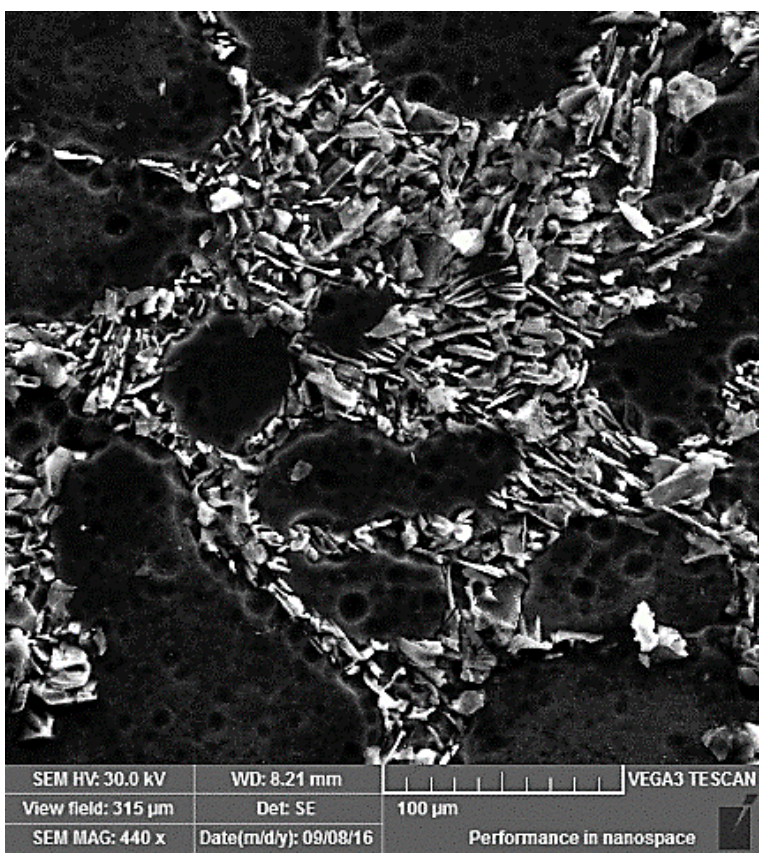

Fig. 8. Eutectic alloys AlSi7Mg0.3 modified calcium (SEM)

grinding and polishing by etching with $10 \%$ sodium hydroxide solution heated to $70^{\circ} \mathrm{C}$ for 60 seconds.

Microstructure of primary alloy Al$\mathrm{Si} \mathrm{Mg} 0.3$ in unmodified condition is shown in Figure 1 and Figure 2. Microstructure of alloy is composed of dendritic cell solid solution $\alpha$ eutectic. Eutectic silicon is in inter- 


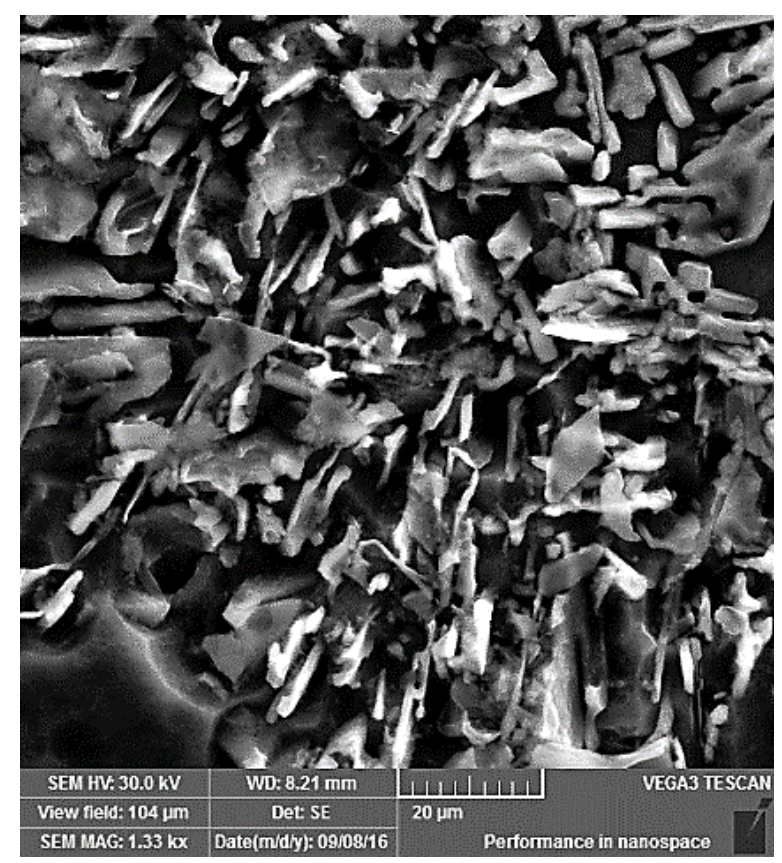

Fig. 9. Eutectic alloys AlSi7Mg0.3 modified calcium (SEM)

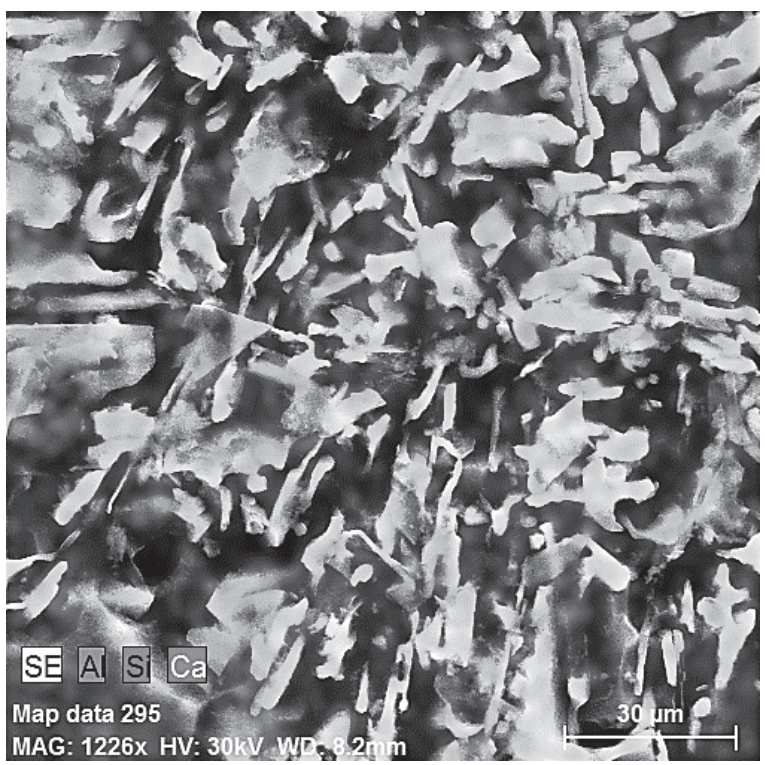

Fig. 10. Elemental map eutectic after modification calcium

dentritic spaces expelled in form coarse hexagonal plates, which are in the palen if metalographic cut appears as needles. Microstructure $\mathrm{AlSi} 7 \mathrm{Mg} 0.3$ modified strontium is shown in Figures 3 and 4. Elemental maps of the area eutectic formed by strontium are in Figures 5,6 and 7.

Microstructure of alloys AlSi7Mg0.3 nodifeid calcium is shown in Figures 8 and 9.

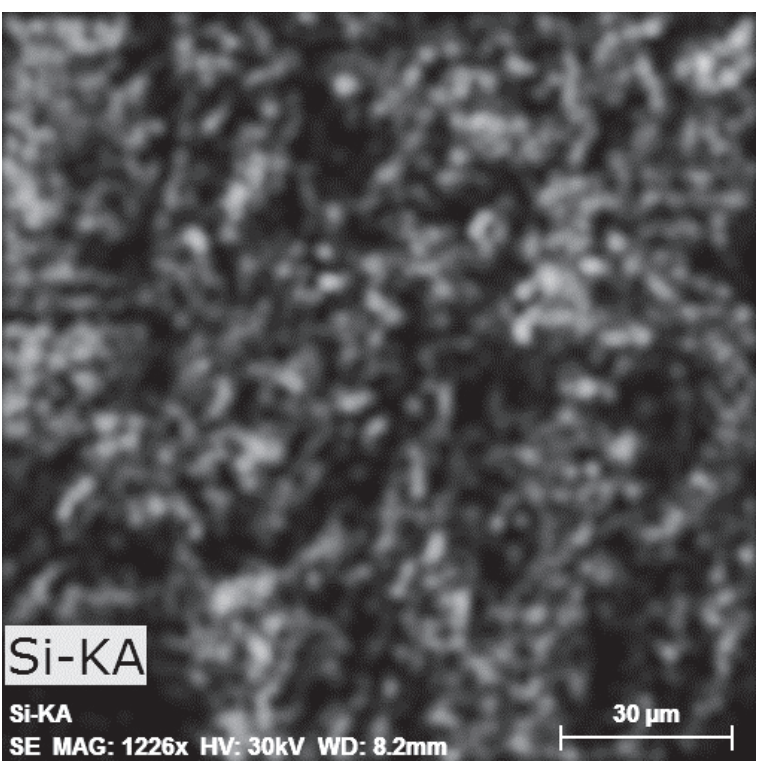

Fig. 11. Elemental map eutectic after modification calcium - silicon

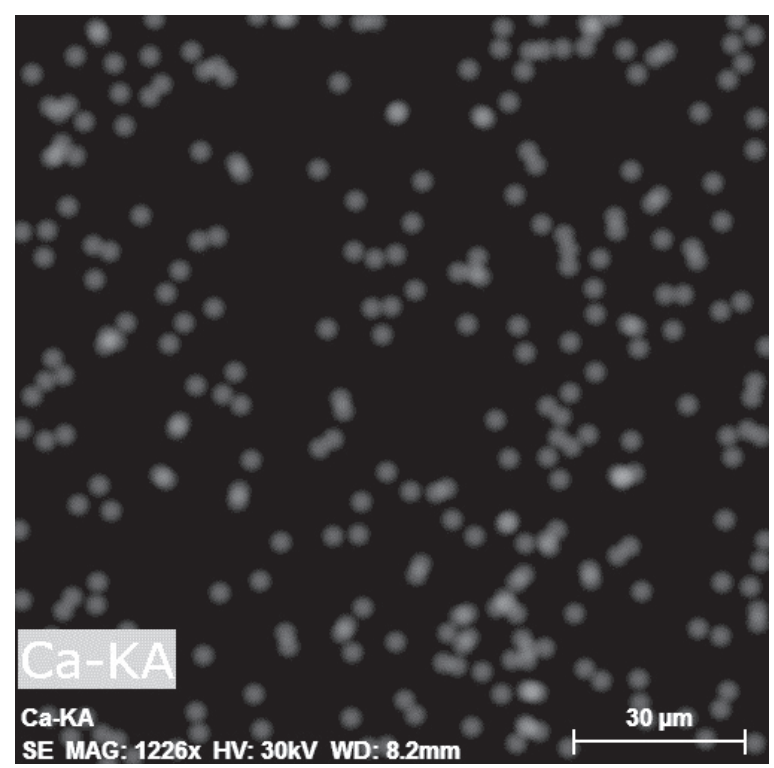

Fig. 12. Elemental map eutectic after modification calcium - strontium

Elemental maps created from the region of eutectic alloy with the modified calcium are designated on Figs. 10 to 12. In the sample of modified calcium was in field eutectic detected intermetallic phases, which were subjected to EDX analysis.

Field on the surface of intermetalic phase, which was subjected to sutface EDX analysisis shown on Figure 13. Quantification of the results of this analysis era shown on Table 5. 


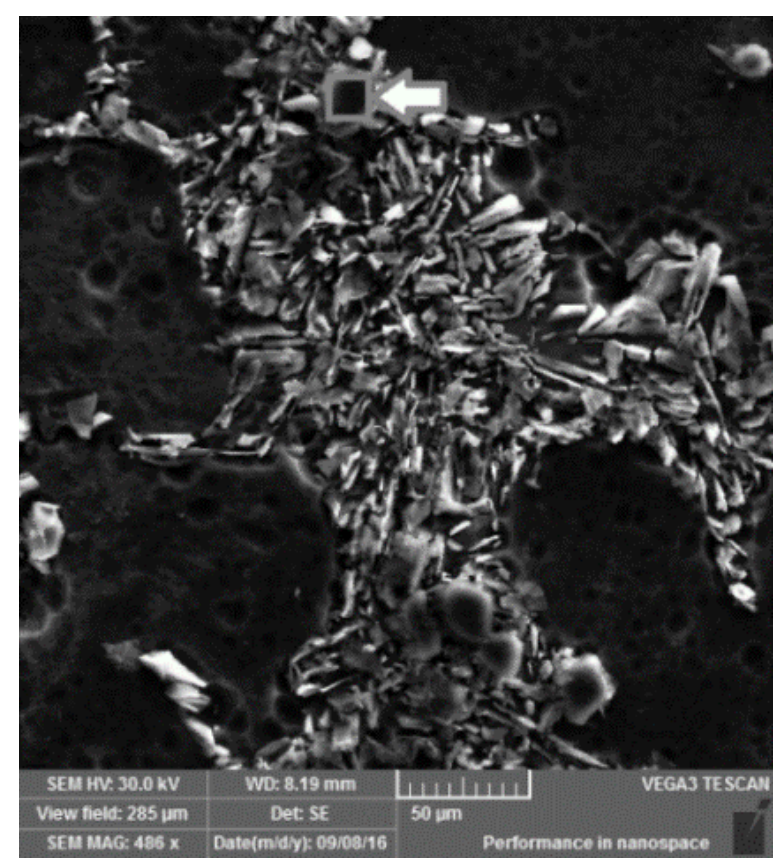

Fig. 13. Oblast povrchu intermetalické fáze pro následnou EDX analýzu

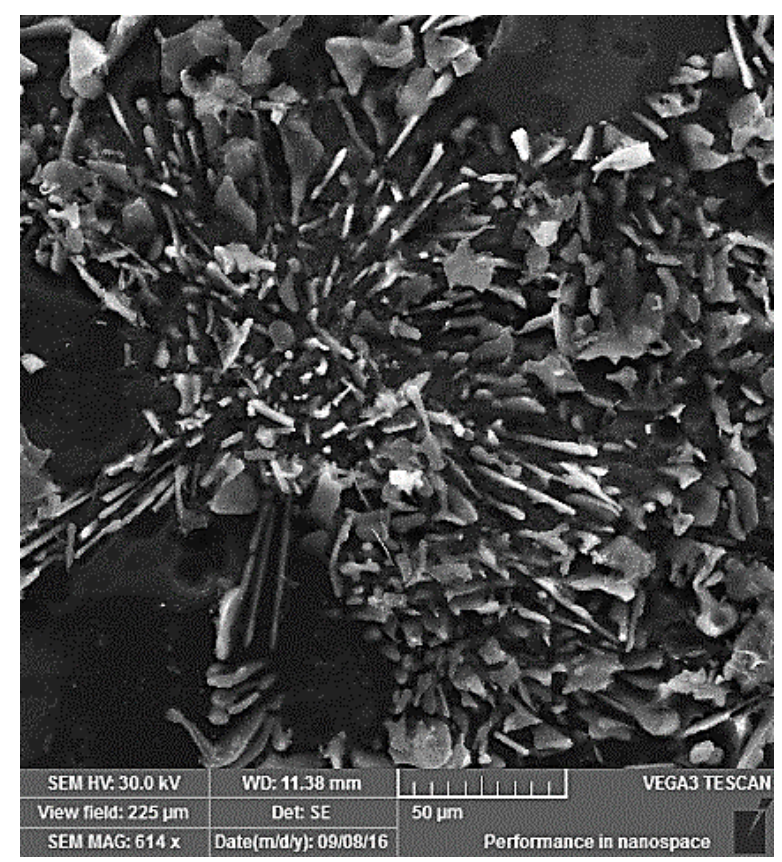

Fig. 14. Microstructure of alloys AlSi7Mg0.3 modified antimony (SEM)

Microstructure of alloys AlSi7Mg0,3 modified antimony is shown in Figure 14 and in Figure 15. Elemental maps created from the region of eutectic alloy with the modified calcium are designated as Figure 16, 17 and 18. In the sample of modified anitimony was conduced EDX analysis

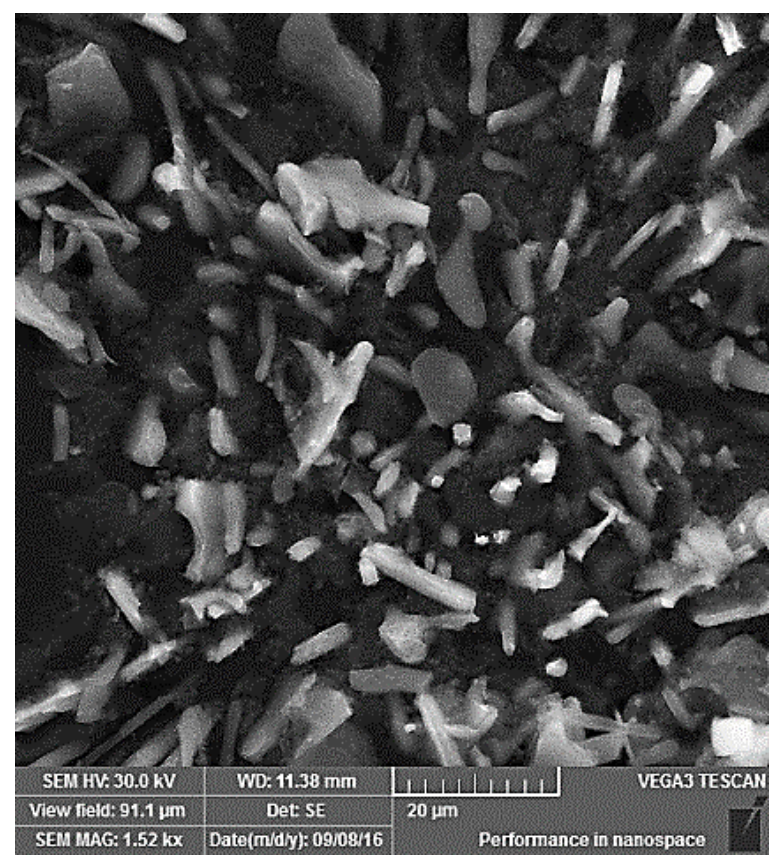

Fig. 15. Microstructure of alloys AlSi7Mg0.3 modified antimony (SEM)

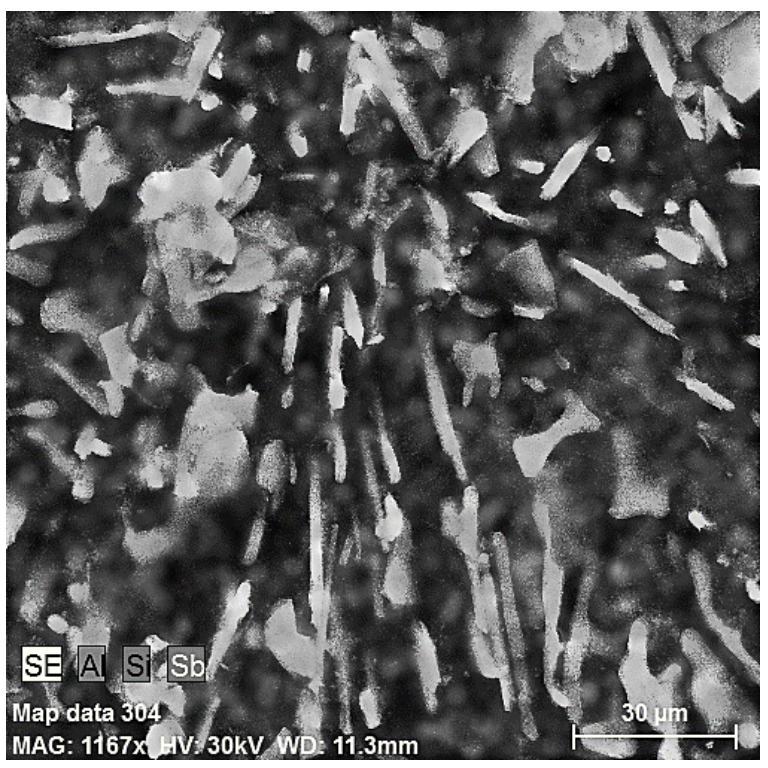

Fig. 16. Elemental map eutectic after modification antimony

Table 5. Quantification of the results of the surfaces EDX analysis - area of analysis in Figure 13

\begin{tabular}{|c|c|c|}
\hline $\begin{array}{c}\text { Chemical element } \\
\text { [wt.\%] }\end{array}$ & $\begin{array}{c}\text { Content of } \\
\text { element [wt.\%] }\end{array}$ & $\begin{array}{c}\text { Content of } \\
\text { element [at.\%] }\end{array}$ \\
\hline Aluminium (K - series) & 37.31 & 41.72 \\
\hline Silicon (K - series) & 3.51 & 37.07 \\
\hline Antimony (L - series) & 28.18 & 21.21 \\
\hline Total & 100 & 100 \\
\hline
\end{tabular}




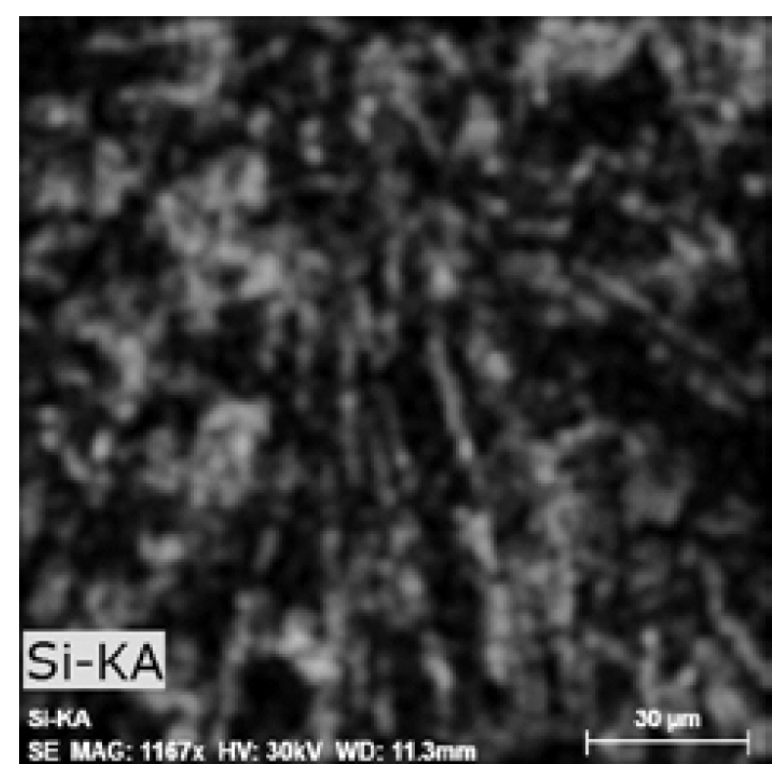

Fig. 17. Elemental map eutectic after modification antimony - silicon

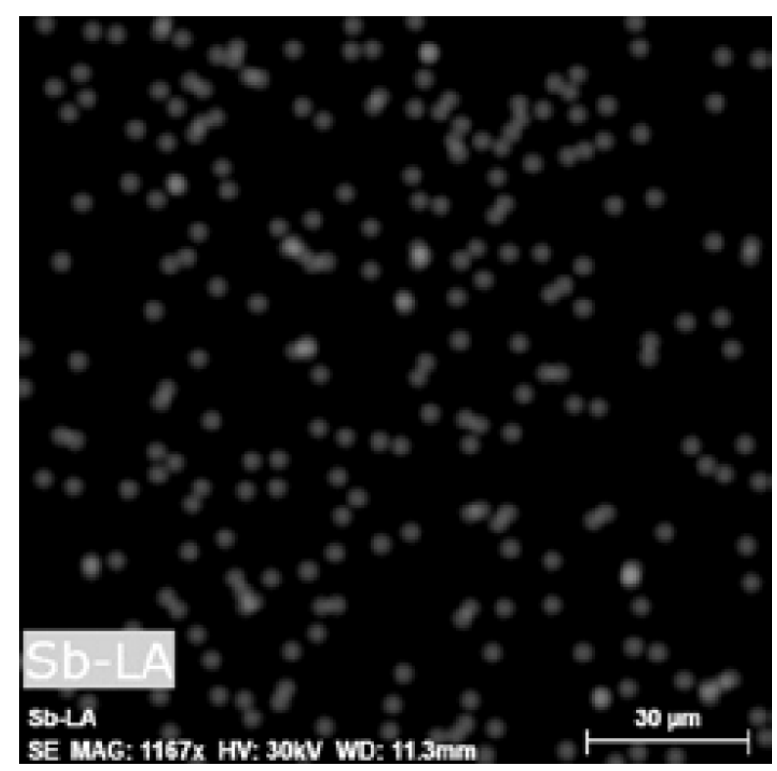

Fig. 18. Elemental map eutectic after modification antimony - strontium

on the surface particles autectic silicon. Point on the surface particles of eutectic silicon, which was subjected to EDX analysis highlighted in Figure 19. Quantification of the results of this analysis are shown in Table 6.

\section{RESULTS AND DISCUSSIONS}

Based on the analysis it can be concluded that the eutectic silicon in the alloy AlSi7Mg0.3

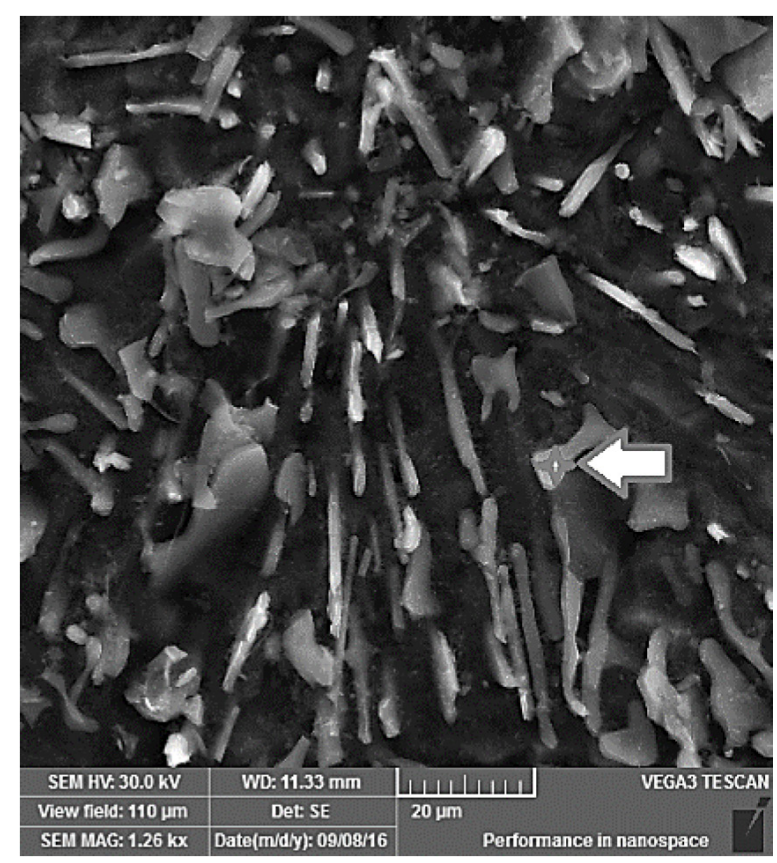

Fig. 19. The point on the surface of the autectic silicon particles for subsequent EDX analysis

Table 6. Quantification of the results of point EDX analysis - point analysis indicated on Fig. 19

\begin{tabular}{|c|c|c|}
\hline $\begin{array}{c}\text { Chemical element } \\
\text { [wt.\%] }\end{array}$ & $\begin{array}{c}\text { Content of } \\
\text { element [wt.\%] }\end{array}$ & $\begin{array}{c}\text { Content of } \\
\text { element [at.\%] }\end{array}$ \\
\hline Aluminium (K - series) & 26.01 & 28.74 \\
\hline Silicon (K - series) & 65.05 & 69.06 \\
\hline Antimony (L - series) & 8.95 & 2.19 \\
\hline Total & 100 & 100 \\
\hline
\end{tabular}

in unmodified condition eliminated as coarse hexagonal plates. The addition of modifiers in the experiment $(\mathrm{Ca}, \mathrm{Sr}$, and $\mathrm{Sb})$ led to a significant change in the morphology of eutectic silicon particles excluded.

The addition of strontium in the alloy AlSi7Mg0.3 concentration 0.027 wt. \% caused the elimination of eutectic silicon in the form of elongated filaments of circular cross the length of tens of micrometers in diameter on the order of micrometers.

Modification of calcium in a concentration of 0.10 wt. \% caused the elimination of eutectic siliconin the form of small thin plates, and locally in the form of fibers having dimensions of units to tens of micrometers. In the alloy modified by calcium, has been further in the area eutectic recognized the presence of intermetalic phase of Al-Si-Ca, namely, it was Al2Si2Ca. 
Modification alloy AlSi7Mg0.3. trough antimony at concentration 0.121 wt. \% caused the elimination of particles eutectic silicon in elongated fibers of circular cross-section (as in the case of strontium modification). EDX analysis carried out on the particle surface eutectic silicon showed the presence of antimony.

\section{CONCLUSIONS}

The results of the examination of the microstructure of the modified alloy AlSi7Mg0,3 by scanning electron microscopy accompanied by EDS analysis confirm the results of previous research. Application of strontium, calcium and antimony as modifiers of higher concentrations of these elements in area eutectic specifically on the surface particles eutectic silicon. The presence of atoms of these elements on the surface of particles of eutectic silicon greatly influences the final morphology of the particles that prevents further flow of the silicon atom to crystallizing nuclei during the crystallization process.

The particles of eutectic silicon examined using modifiers have significantly different morphology compared to the unmodified alloy. In all cases, the eutectic silicon eliminated as much finer and rounder particles than those of the unmodified alloy (silicon in the microstructure eliminated as coarse hexagonal plates). Exactly change the morphology of the particles of silicon is the basic prerequisite for a significant increase in ductility alloy which is cast in the state without modification application process is low.

\section{Acknowledgement}

This article was created due to the project nr. 4820215001001 „SGS“ under the specific university research on FVTM JEPU.

\section{REFERENCES}

1. Makhlouf M., Guthzy H. The aluminum-silicon eutectic reaction: mechanisms and crystallography, Journal of Light Metals, 2001, No. 1, 199-218.

2. Dahle A., Nogita K., McDonald S., Dinnis C., LU L. Eutectic modification and microstructure development in Al-Si Alloys, Materials Science and Engineering A, 2005, 243-248.

3. Nogita K., Dahle A. Eutectic Growth Mode in Strontium, Antimony and Phosphorus Modified Hypoeutectic Al-Si Foundry Alloys, Materials Transactions, 2001, 42(3), 393-396.

4. Xiufang B., Weimin W., Jingyu Q. Liquid structure of $\mathrm{Al} \pm 12.5 \%$ Si alloy modified by antimony, Materials Characterization, 2001, 21-25.

5. Knuutinen A., Nogita K., McDonald S., Dahle A. Modification of $\mathrm{Al}-\mathrm{Si}$ alloys with $\mathrm{Ba}, \mathrm{Ca}, \mathrm{Y}$ and Yb, Journal of Light Metals, 2001, 229-240.

6. Náprstková N., Cais J., Ingaldi M.: Modification of AlSi9CuMnNi Alloy by Antimony and Heat Treatment and Their Influence on Tool Wear after Turning, Manufacturing Technology, 2016, 16(1), 209-214.

7. Náprstková N., Cais J., Svobodová J.: The Effect of Modification by Strontium of the AlSi7Mg0.3 Alloy on the Surface Roughness, Manufacturing Technology, Journal for Science, Research and Production, October 2013, 13(3), 380-384.

8. Michna Š., Honzátko R., Cais J.: Analysis of Causes $\mathrm{Al} 2 \mathrm{MgO} 4$ - Type Spinel Inclusion Formation in Low-Pressure Casting, Manufacturing Technology, 2013, 13(3), 361-368. 